\title{
Looking at Patients and Listening to Patients in Time of Technological Innovation
}

\author{
Luciana de Barros Correia Fontes* \\ Department of Clinic and Preventive Dentistry, Federal University of Pernambuco, Brazil
}

Received: 制 January 22, 2018; Published: 粗January 30, 2018

*Corresponding author: Luciana de Barros Correia Fontes, Department of Clinic and Preventive Dentistry, Federal University of Pernambuco, Brazil

\section{Editorial}

We are in a globalized world, with fast and extensive changes, particularly in the appropriate use of technology in medical problems. The search for early diagnosis and treatment goes through a range of increasingly complex exams and interventions, based on technological advances. Smart phone interaction has the pontencial to improve clinical case discussion, for example. However some controversies persist: Are these advances also associated with patients satisfaction with quality of care received, according to their needs and perspectives? Several factors affecting negatively the effective communication between patients and health professionals as the limitations imposed by listeners

and difficulty developing language skills and understanding. In the context of what has been described previously, looking at the individual and effectively understanding beyond first impressions represents one of the fundamental basis for healthcare, but not usually. Listening is presented as another essential communication strategy for relationship between health professional and their patients. It is considered therapeutic because of the reduction of anxieties, stress and suffering of the assisted, bythe dialogue. Therefore is very important a qualified listening and embracement in health practice. Technological resources must be expanded and improved, increasing our interpersonal relationship.
(C) This work is licensed under Creative

To Submit Your Article Click Here: Submit Article
DOI: 10.32474/MADOHC.2018.01.000107

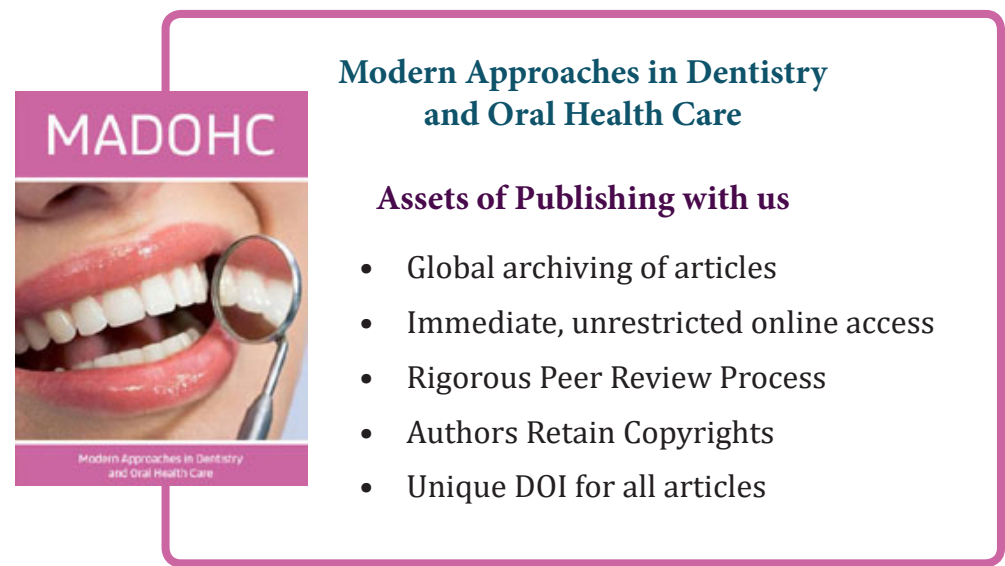

